never err, that if there is much heat of stomach, much tenderness in the epigastric region, and, more especially, an increase of heat there on pressure, you will be right in treating the case antiphlogistically, immediately debarring your patient from every stimulating article of drink and food, and applying leeches to the pit of the stomach, or, if the pulse warrants it, abstracting blood from the arm. Supposing that you commit an error in diagnosis, and that it is only functional derangenent (and I admit that sometimes it is difficult accurately to distinguish), you can do your patient no harm by the restriction of his regimen, the application of a few leeches, and employing counter-irritation; but you may do infinite mischief, under the idea of the case being merely one of a weak condition of the stomach, by giving stimulants and tonics, prescribing carbonate of ammonia, allowing brandy-and-water, advising an increase in the daily quantity of his wine, and permitting him to live a little more "generously."

\title{
CASE OF PARTIAL AMAUROSIS FROM NARCOTICŚ.
}

BY EDWARD J. DAVENPORT, M.D.

[Communicated for the Boston Medical and Surgical Journal.]

Winifred Comans, aged 15, applied for advice during the summer of 1835, on account of a weakness of sight, which had been experienced from childhood. The complaint seemed to be analogous to that known under the name of morbid sensibility of the retina; marked in this case by inability to apply the eyes to small objects, as in reading, sewing, \&c. The continued effort to do this, occasioned uneasy feelings in the eyeballs, accompanied with a confusion or running together of objects, and a general dimness or temporary loss of vision. This had increased of late, and was attended with well-marked Presbyopia. The discovery of this state of the organ of vision was owing to the patient's trying the convex or magnifying glasses of an aged person. The use of these glasses benefited vision in a measure, but did not by any means remove the difficulty. There were neither muscæ volitantes nor luminous spectra; nor was the application of the eyes, as happens in many instances, attended with pain in the eyeball, and a sense of stricture across the forehead. There was a slight redness of the conjunctiva, especially of that portion of the membrane lining the eyelids. The corneæ were clear and transparent, but apparently were neither preternaturally convex nor too much flattened. The irides, however, deviated from a plane, and were remarkably convex, approximating to a cone with its apex towards the cornea. The pupils were contracted, and did not vary much when under the influence of a strong light. Deep-seated humors not opaque. Iris of a blue color. Health good.

When very young, she had the smallpox in its severest form, to which it is not unlikely the weakness of sight may be attributed; although her mother does not recollect that any ophthalinia attended the attack. All the other members of the family have good vision.

A few days since, this patient again applied for advice, with the pupil of the right eye dilated to the utmost extent and entirely motionless; at 
the same time the power of vision was so much impaired, that she was unable to distinguish common print at all, while the sight and the general state of the opposite eye remained as before. The dilatation of the pupil and the impaired vision of the right eye, occurred a few hours only previous to application, and the patient cculd assign no cause, except that she had grot some dust into her eyes, which had occasioned a slight irritation of the tunica conjunctiva. She had, however, been in the habit lately of sewing considerably, without the aid of glasses. No pain was present, either in the eye or in the neighboring parts. There were neither muscæ nor luminous spectra, but merely an appearance as if a nist or cloud intervened between the eye and every object. The iris seemed to be perfectly insensible to the stimulus of light, but the pupil remained clear and transparent. By desire of the patient, active treatment was postponed until the next day, but in the mean time she was directed to apply tepid fomentations to allay the irritation caused by the dust, and to give the eye rest.

Two days afterwards it was found that the pupil of the affected eye was perfectly restored to its former condition, and now corresponded in all respects with that of the opposite eye. The power of vision had also returned to its previous state. This recovery had taken place gradually and spontaneously, the day after her application.

Upon more minute inquiry into the cause of the morbid appearances noticed the first day, the patient recollected that she had handled and examined, at that time, some " ointment" formerly prescribed by a physician for her eyes. And she also stated that, by his direction, a sinall portion of the ointment was put into her eyes, after which she experienced a dimness of vision as at present, in consequence of which she had made no further use of it. That this "ointment" was an extract or some other preparation of belladonna or stramonium, is self-evident; and that some of it had been communicated to the eye accidentally, is more than probable. It is well known that gonorrheal, and very frequently purulent ophthalmias, have originated from matter conveyed to the eye by the hands or clothes of those affected. So in this case, some of the extract seems to have been carried to the eye, perhaps by rubbing it with the hand, and thus occasioned the above mentioned phenomena.

That vision should be materially impaired, by the artificial dilatation of the pupil for a short period, is certainly an unusual circumstance, theorizing dogmas upon the protecting offices of the pupil to the contrary notwithstanding. It may be explained, in the present case, by reference to the pre-existing derangensent of the functions of the retiua. The pupil, as before remarked, was preternaturally contracted, and the iris limited in its motions; evidences-though taken alone, not conclusiveof some morbid change in the retina, either functional or organic. Considering how infrequent it is to find one eye alone attacked suddenly with amaurosis, it may excite surprise that the true cause of the morbid appearances was not suspected. Be that as it may, the circumstances are narrated as they occurred, partly as a matter of curiosity, and partly 
as an example of the delusive nature of symptoms, regarded as evidences of the actual occurrence of disease.

In two other cases only have I noticed any analogous effects from the application of stramonium or belladonna, and those occurred in females somewhat advanced in life, in both of whom there were previously symptoms of disease in the optic apparatus. In one of these, amaurosis seemed to be conjoined with glaucoma, and in this case the iris did not regain its usual activity, after a single application of extract of stramonium, until the eighth day, during which time vision remained more or less impaired. This patient had been long presbyopic, and the iris had the prominent or cone-like form in a remarkable degree-so much so, indeed, as to appear to be in close contact with the posterior surface of the cornea. The pupil was also somewhat contracted, and the iris was rather sluggish in its motions. In each instance, the increased dimness of vision ceased with the restoration of the pupil to its former state. In these cases, it may be observed that the stramonium was not applied as a remedial agent, but merely to assist in forming a correct diagnosis of the disease.

Boston, June, 1836.

\section{INSECT DISSECTIONS.}

\section{To the Editor of the Boston Medical and Surgical Journal.}

SIR-Various means have hitherto been prescribed for killing the Lepidopterous insects previous to their preparation for the cabinet; but 1 have found all of them, on trial, to be objectionable, and was led some time since to devise the following expeditious method. The insect is seized with the thumb and finger, by the under side of the anterior wings, near the margin, and while thus securely held from fluttering, is injected with a solution of oxalic acid, by a sharpened capillary glass tube which readily pierces the under side of the thorax. The tubes are from six to eight inches in length, of small bore and very thin. They must be drawn out to a closed bore in the flame of a lamp, and the attenuated end then broken off, until the bore becomes perceptible and sufficiently large to admit the acid to rise without exhausting them by the mouth. The injection is performed by the mouth. The female moth, so tenacious of life before depositing her eggs, expires instantly under this treatment. I have now put this experiment to a fair test. Butterflies and moths, killed in this way more than three years ago, appear as fresh as when first taken. While injecting a large butterfly (Papilir Asterias) in this way, the double membranes of its wings yielded and became perfectly inflated, and is now preserved in this state, with its wings looking like so many sacs. While injecting a small moth, a curious organ was observed. Two cæcal membranous tubes were projected from its anal ring, each half an inch in length and covered with short sparse hairs. They retracted entirely within the body as soon as the injection ceased, and could be made to reappear at pleasure. 